\title{
Neutron noise experiments in the AKR-2 and CROCUS reactors for the European project CORTEX
}

\author{
Vincent Lamirand ${ }^{1,2}$, Adolfo Rais ${ }^{1}$, Sebastian Hübner ${ }^{3}$, Carsten Lange ${ }^{3}$, Joachim Pohlus ${ }^{4}$, \\ Uwe Paquee ${ }^{4}$, Christoph Pohl ${ }^{5}$, Oskari Pakari ${ }^{1}$, Pavel Frajtag ${ }^{1}$, Daniel Godat ${ }^{1}$, Mathieu Hursin ${ }^{1,2}$, Axel Laureau ${ }^{1}$, \\ Grégory Perret ${ }^{2}$, Carlo Fiorina ${ }^{1}$, Andreas Pautz ${ }^{1,2}$
}

\begin{abstract}
The present article gives an overview of the first experimental campaigns carried out in the AKR-2 and CROCUS reactors within the framework of the Horizon 2020 European project CORTEX. CORTEX aims at developing innovative core monitoring techniques that allow detecting anomalies in nuclear reactors, e.g. excessive vibrations of core internals. The technique will be mainly based on using the fluctuations in neutron flux, i.e. noise analysis. The project will result in a deepened understanding of the physical processes involved. This will allow utilities to detect operational problems at a very early stage, and to take proper actions before such problems have any adverse effect on plant safety and reliability. The purpose of the experimental campaigns in the AKR-2 and CROCUS reactors is to produce noise-specific experimental data for the validation of the neutron noise computational models developed within this framework. The first campaigns at both facilities consisted in measurements at reference static states, and with the addition of mechanical perturbations. In the AKR-2 reactor, perturbations were induced by two devices: a rotating absorber and a vibrating absorber, both sets in experimental channels close to the core. In CROCUS, the project benefited from the COLIBRI experimental program: 18 periphery fuel rods were oscillated at a maximum of $\pm 2 \mathrm{~mm}$ around their central position in the $\mathrm{Hz}$ range. The present article documents the experimental setups and measurements for each facility and perturbation type.
\end{abstract}

Keywords - Core monitoring and diagnostics, noise analysis, research reactor experiment, zero-power reactor

\section{INTRODUCTION}

HE Horizon 2020 European project CORTEX aims at Tr

developing innovative core monitoring techniques that allow detecting anomalies in nuclear reactors, such as excessive vibrations of core internals, flow blockage, or coolant inlet perturbations [1]. The technique will be mainly based on using

The research leading to the results hereby documented has received funding from the Euratom research and training programme 2014-2018 under grant agreement No 754316 (i.e., CORTEX).

*V. Lamirand, A. Rais, O. Pakari, P. Frajtag, D. Godat, M. Hursin, A. Laureau, C. Fiorina, and A. Pautz are with the Laboratory for Reactor Physics and Systems behaviour (LRS), Ecole Polytechnique Fédérale de Lausanne (EPFL), CH-1015 Lausanne, Switzerland (*corresponding author: vincent.lamirand@epfl.ch). the inherent fluctuations in neutron flux recorded by in-core and ex-core instrumentation, from which the anomalies will be differentiated depending on their type, location and characteristics. The method is non-intrusive and does not require any external perturbation of the system. The project will result in a deepened understanding of the physical processes involved. This will allow utilities to detect operational problems at a very early stage, and to take proper actions before such problems have any adverse effect on plant safety and reliability.

In this framework, computer methods and models are developed. The purpose of the experimental campaigns at the AKR-2 and CROCUS reactors is to produce high quality noisespecific experimental data for the validation of these neutron noise computational models. The AKR-2 reactor at Technische Universität Dresden (TUD) is a thermal, homogeneous, polyethylene moderated zero-power reactor with an allowed maximum continuous power of $2 \mathrm{~W}$. The CROCUS reactor at the École Polytechnique Fédérale de Lausanne (EPFL) is a twozone, uranium-fueled, and light water-moderated facility. With a maximum power of $100 \mathrm{~W}$, it is a zero-power reactor used for teaching and research purposes, currently with a focus on studies on intrinsic and induced neutron noise [2]-[4].

The first campaigns at both facilities consisted in measurements at reference static states, and with the addition of mechanical perturbations. In the AKR-2 reactor, perturbations were induced by two devices: a rotating absorber and a vibrating absorber, both sets in experimental channels close to the core. In CROCUS, the project benefited from the COLIBRI experimental program: up to 18 periphery fuel rods are oscillated at a maximum of $\pm 2.5 \mathrm{~mm}$ around their central position in the $\mathrm{Hz}$ range. The present article documents the experimental setups and measurement campaign for each facility and perturbation type.

S. Hübner and C. Lange are with the Institute of Power Engineering, Technische Universität Dresden, 01062 Dresden, Germany.

J. Pohlus and U. Paquee are with the Institut fur Sicherheitstechnologie GmbH (ISTec), 85748 Garching, Germany.

C. Pohl is with TÜV Rheinland Industrie Service GmbH (TUV), 51105 Cologne, Germany.

V. Lamirand, M. Hursin, G. Perret, and A. Pautz are with the Nuclear Energy and Safety Research Division (NES), Paul Scherrer Institut (PSI), CH-5232 Villigen, Switzerland. 


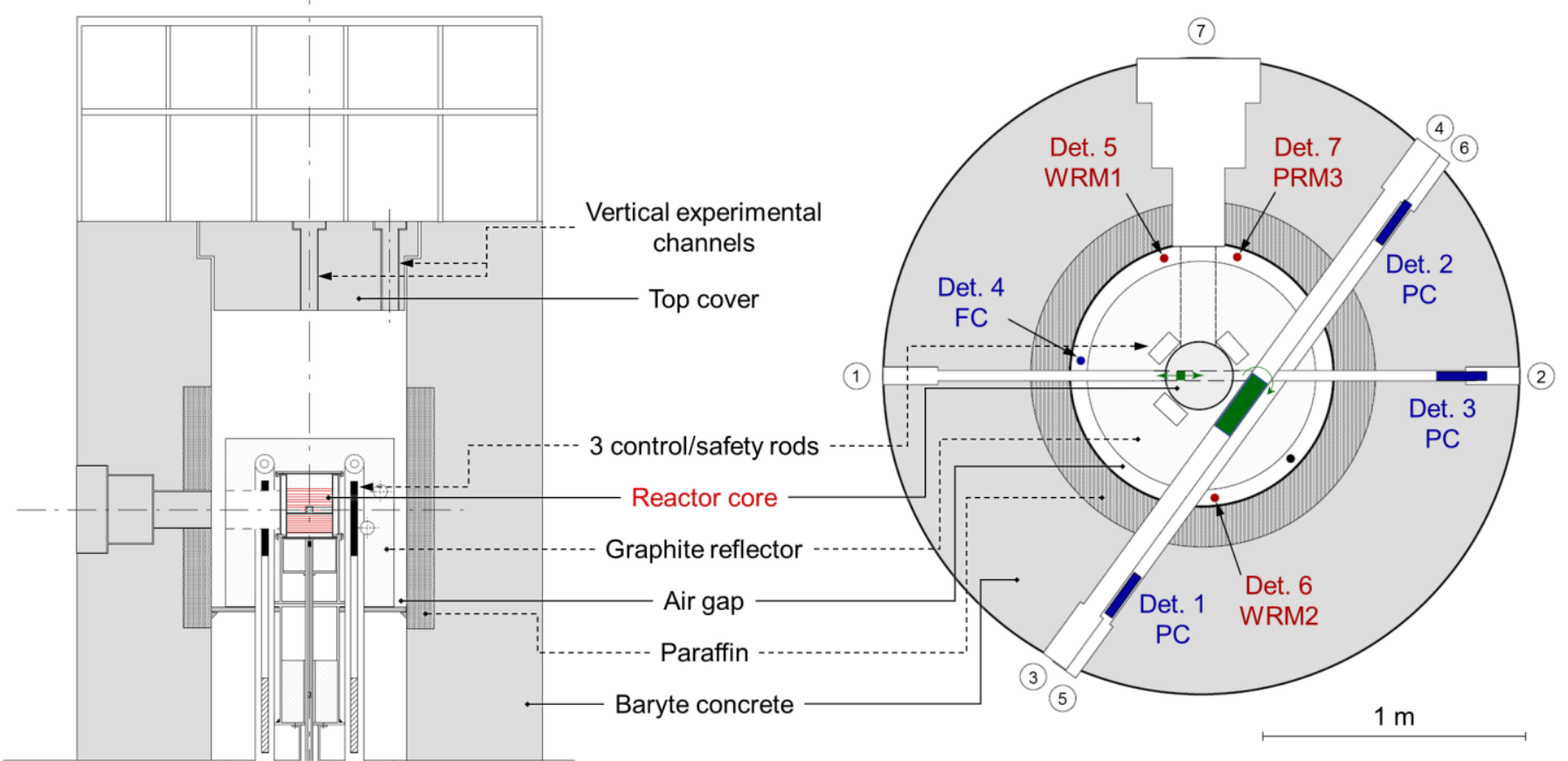

Fig. 1. The AKR-2 reactor: on the left, side cross section; on the right, cross section showing components, experimental channels (numbers), perturbation devices (green), and neutron detection instrumentation (blue and red).

\section{FIRST EXPERIMENTAL CAMPAIGN IN AKR-2}

The first experimental campaign in the AKR-2 reactor took place from 6 to 15 March 2018. Two types of experiments were carried out to induce neutron flux oscillations: rotation of a thermal neutron absorber (of variable absorption with respect to the rotation angle) and linear moving of an absorber oscillating back and forth in the reactor core (a.k.a. vibrating absorber).

\section{A. The AKR-2 reactor}

The AKR-2 reactor of TU Dresden (TUD) is a thermal, homogeneous, polyethylene moderated zero-power reactor with an allowed maximum continuous thermal power of $2 \mathrm{~W}$ [5]. The core has cylindrical shape with a diameter of 250 $\mathrm{mm}$ and a critical height of $275 \mathrm{~mm}$. The disk-shaped fuel elements consist of a homogeneous dispersion of polyethylene and uranium oxide $-19.8 \%$ enriched in ${ }^{235} \mathrm{U}$, with and $\mathrm{O}$-to-U ratio of 2.27 . The ${ }^{235} \mathrm{U}$ density in the fuel elements amounts to $0.060 \mathrm{~g} / \mathrm{cm}^{3}$. The core is surrounded by a graphite reflector with a density of $1.75 \mathrm{~g} / \mathrm{cm} 3$ (see Figure 1). The axial and radial thicknesses are 20 and $32 \mathrm{~cm}$, respectively. Therefore, the critical mass is relatively small (about $790 \mathrm{~g}$ of ${ }^{235} \mathrm{U}$ ). Within certain constraints, it is a minimum-critical-mass reactor.

For safety reasons, the core consists of two separable sections. The fuel elements of each section are enclosed in a hermetically sealed aluminum container. In the shut-down position the distance between the lower and the upper core section is about $50 \mathrm{~mm}$. The lower section is lifted by means of a core drive mechanism including an electromagnetic holder of the core section. Through a tube within this mechanism the start-up neutron source (Am-Be, neutron yield $2.2 \cdot 10^{6} \mathrm{n} / \mathrm{s}$ ) is moved from the source container to the bottom side of the core. The distance between the bottom side of the core and the middle of the source container measures about $800 \mathrm{~mm}$.
The reactor is controlled by three cadmium absorber plates. These plates are moved vertically in a gap within the reflector outside the reactor tank. They are designed as combined control and safety rods. An automatic reactor power control is available using the control rods. The lower core section and the control rods are held by electromagnets in their normal-operation positions. Any scram signal opens the direct-pull holding magnets allowing the rods and the lower core section to fall in the shut-down position by gravity.

The reactor core, reactor tank, graphite reflector and control rods are arranged on a horizontal steel plate (diameter $1000 \mathrm{~mm}$, thickness $30 \mathrm{~mm}$ ) inside the reactor vessel. This is a cylindrical double-walled vessel containing the biological shield and having an outer diameter of $2500 \mathrm{~mm}$ and a height of $2800 \mathrm{~mm}$.

There are four horizontal and two vertical experimental channels with different diameters and shapes. They provide adequate in-pile irradiation volume with different neutron spectra. At $2 \mathrm{~W}$ power level, the maximum flux density of thermal neutrons in the central experimental channel 1-2 (see Figure 1) is about $2.5 \cdot 10^{7} \mathrm{~cm}^{-2} \cdot \mathrm{s}^{-1}$.

\section{B. Neutron detection instrumentation}

The nuclear instrumentation used for the first campaign of measurements at the AKR-2 reactor is comprised by seven detection channels from which the neutron flux level in the reactor is inferred, their locations are shown in Figure 1 (right):

- $\quad$ Three ${ }^{3} \mathrm{He}$ proportional counters (PC)

- $\quad$ One ${ }^{235} \mathrm{U}$ fission chamber $(\mathrm{FC})$

- Two logarithmic wide-range monitors (WRM1 and 2), ${ }^{235} \mathrm{U}$ fission chambers

- One linear power-range monitor (PRM3), gammacompensated ionization chamber 
It is worth noting that the three latter channels comprise the reactor instrumentation for safety and reactor monitoring purposes. These detectors are shown in red color in Figure 1.

Three independent data acquisition systems (DAQ) were provided by TUD, EPFL and ISTec and used during the measurements for signal readout and storage. The complete neutron detection sequence with the associated electronics is available in [6].

\section{Experiments}

The experiments at the AKR-2 reactor consisted in introducing two different sources of periodic reactivity perturbations that induce neutron flux oscillations. The first type of perturbation is generated by a rotating neutron absorber that has a varying absorption cross-section with respect to the rotation angle, and the second one by a linearly oscillating absorber that is moved back and forth inside the reactor core (vibrating absorber). In addition to the seven neutron detection signals, three other signals were measured and recorded:

- linearly moving absorber position as a function of time,

- inductive proximity sensor's signal to detect the rotation,

- external TTL signal for synchronization purposes.

\section{1) Rotating absorber experiments}

In order to maximize the perturbation induced to the neutron flux, the rotating absorber shaft was inserted in a location where the gradient of the neutron flux is maximum: i.e., the tangential line (channel 3-4). The reactivity worth of the absorber was measured and is presented in Appendix 7.6.1.

The geometry description and mechanical arrangement of the rotating absorber are summarized below:

- absorber material: natural cadmium (with impurities),

- dimensions of cadmium sheet (cm): $25 \times 2 \times 0.02$,

- rotation axis location: tangential channel 3-4,

- rotation axis distance with respect to core center: $22 \mathrm{~cm}$ in the radial direction and $8 \mathrm{~cm}$ above in height,

- $\mathrm{Cd}$ sheet distance with respect to rotation axis: $2.98 \mathrm{~cm}$.

The experimental arrangement is illustrated in Figure 2, presenting two section views of the rotating absorber with geometrical details. The static reactivity worth of the absorber was measured and is about $11 \mathrm{ct}$ in total. The rotation speed was kept constant while measuring. The experiments were carried out at a frequency range from 0.2 to $2 \mathrm{~Hz}$. The rotation was measured by an inductive proximity sensor, which yielded a pulsed signal per revolution.

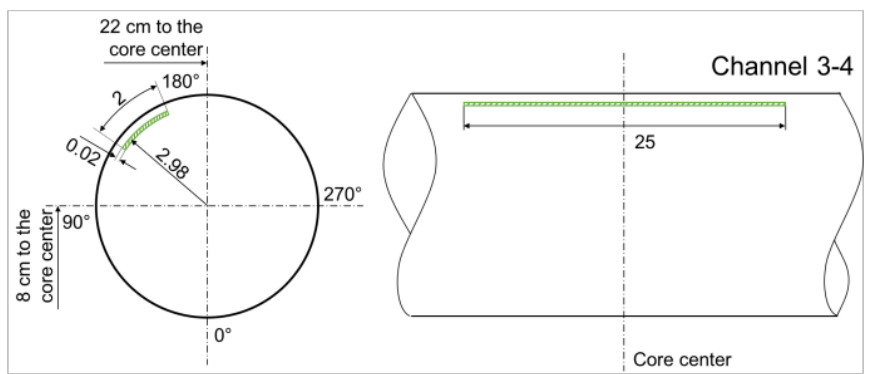

Fig. 2. Cross and longitudinal views of the rotating absorber in channel 3-4 (units in $\mathrm{cm}$ ).

\section{2) Vibrating absorber experiments}

A pneumatic-driven vibrating absorber was employed to linearly oscillate a neutron absorber back and forth inside the reactor core. The absorber is moved along the experimental channel 1-2, between a position inside the core and a position outside the core as illustrated in Figures 1 and 3. The static reactivity worth of the absorber was measured at $13 \mathrm{ct}$ in total. The material and geometry data for the absorber are summarized below:

- linear motion axis: radial channel 1-2 at core mid-height,

- absorber thickness: $1.016 \mathrm{~mm}$,

- absorber diameter: $12.7 \mathrm{~mm}$,

- absorber material: $99.97 \%$ natural Cd plus impurities.

The periodic motion of the vibrating absorber is defined by two main parameters: the waiting and moving time as shown in Figure 3 . The pneumatic system allows to modify the absorbers motion by varying the moving time $\left(\mathrm{t}_{\mathrm{m}}\right)$ from 0.4 to 2.0 seconds, and/or the waiting time $\left(t_{\mathrm{w}}\right)$ from 0.1 to 4.0 seconds. By tuning these parameters, the experiments were carried out at a frequency range from 0.08 to $0.71 \mathrm{~Hz}$. The relative position of the vibrating absorber was recorded along.

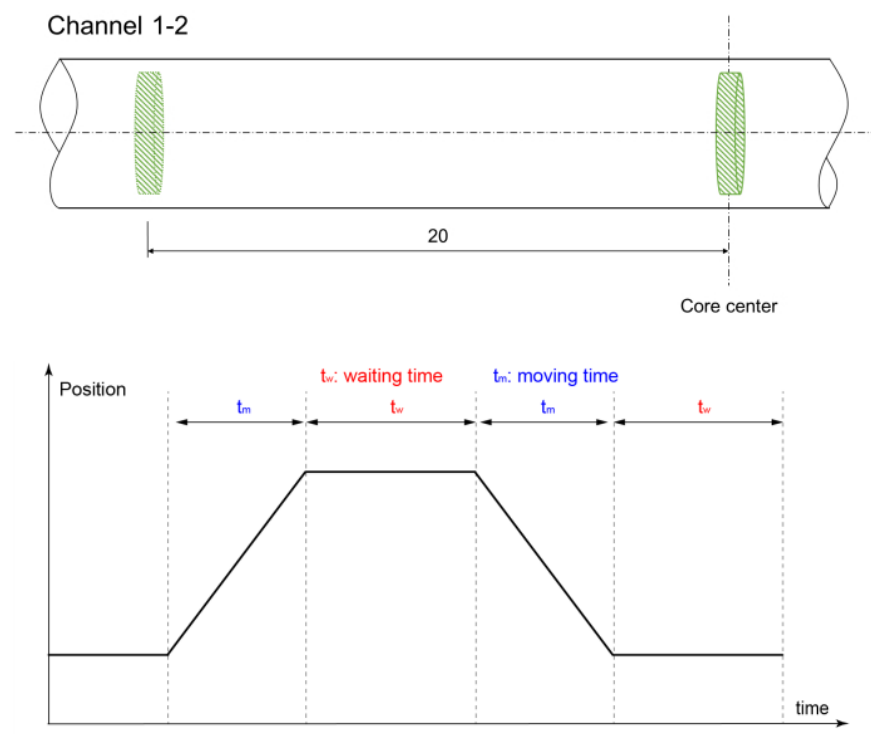

Fig. 3. On the top, side view of the absorber motion path in channel 1-2 (units in $\mathrm{cm}$ ). On the bottom, trapezoidal motion followed by the absorber in the experiments.

\section{FIRST EXPERIMENTAL CAMPAIGN IN CROCUS}

The first experimental campaign in the CROCUS reactor took place from 17 to 21 September 2018. Vibrating fuel rods experiments were carried out using an in-core device that was specifically developed for that purpose [7], [8]. This section describes the CROCUS reactor, the experimental setup, and the vibrating fuel rods experiments.

\section{A. The CROCUS reactor}

CROCUS at the École Polytechnique Fédérale de Lausanne (EPFL) is an experimental zero-power reactor, uranium-fueled and light water-moderated, dedicated to teaching radiation and reactor physics, and to research. A complete description of the 


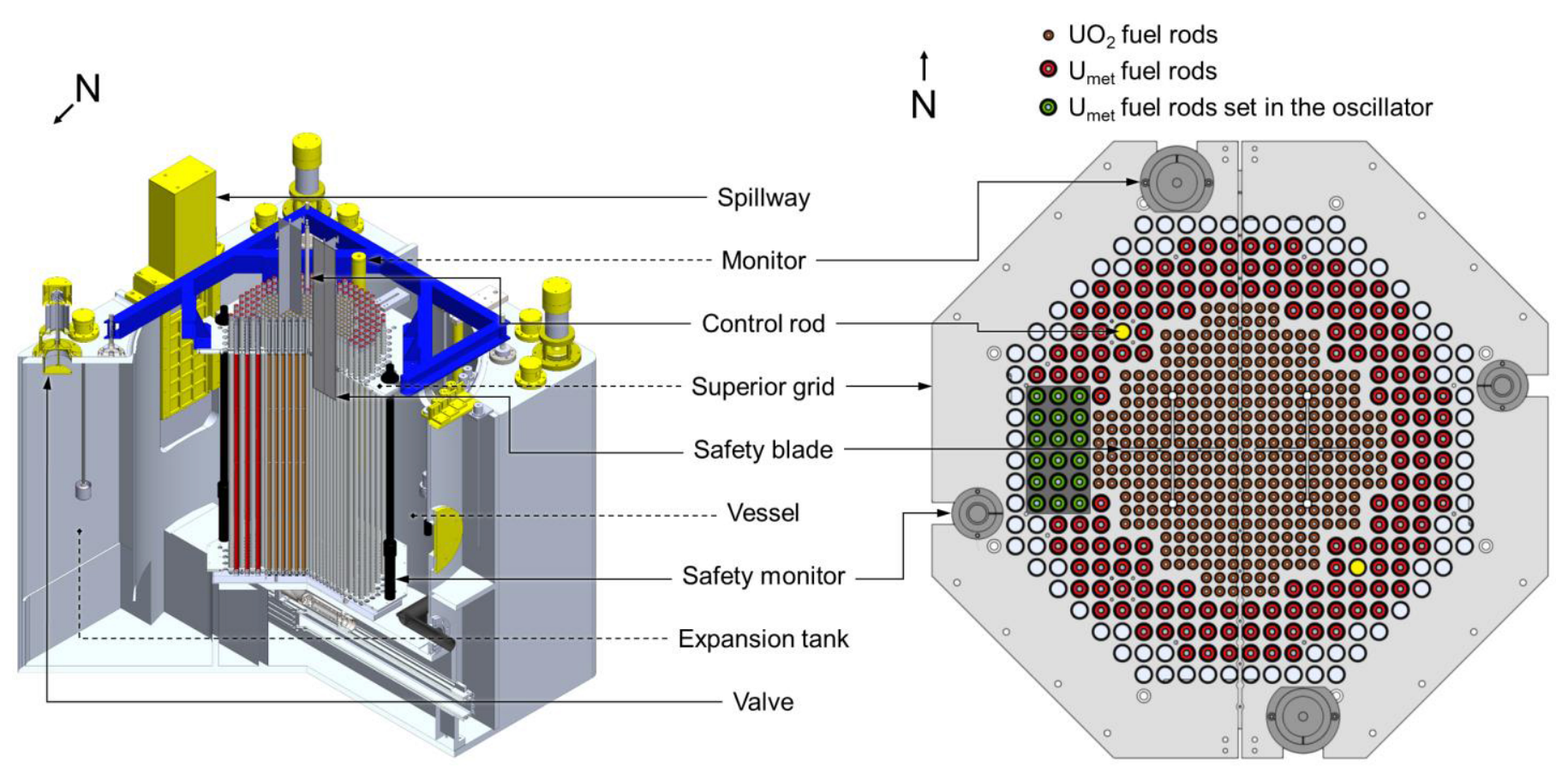

Fig. 4. The CROCUS reactor: isometric view of the vessel (left), and top view of the core superior grid and configuration, with the indication of the location of the fuel rods set in the oscillator (green).

core can be found in the International Reactor Physics Experiments Handbook (IRPhE) [9], [10]. It has been licensed for operating at a maximum power of $100 \mathrm{~W}$, i.e. a total neutron flux of $\sim 2.5 \cdot 10^{9} \mathrm{~cm}^{-2} \cdot \mathrm{s}^{-1}$ at the core center. Criticality is controlled either by water level using a spillway, or by two $\mathrm{B}_{4} \mathrm{C}$ absorber control rods, with an accuracy of $\pm 0.1 \mathrm{~mm}$ (equivalent to approximately $\pm 0.4 \mathrm{pcm})$ and $\pm 0.5 \mathrm{~mm}( \pm 0.2 \mathrm{pcm})$, respectively. CROCUS operates at room temperature using a controlled water loop with secondary and tertiary circuits, two heat exchangers and an electrical heater.

The core is located in an Al-6060 grade vessel of $130 \mathrm{~cm}$ in diameter, $160 \mathrm{~cm}$ in height, and $1.2 \mathrm{~cm}$ in thickness. The vessel is filled with demineralized light water used as both moderator and reflector. The core active part has the approximate shape of a cylinder of $100 \mathrm{~cm} \mathrm{~m}$ in height and about $60 \mathrm{~cm}$ in diameter. It consists of two interlocked fuel zones with square lattices of different pitches: an inner zone of $336 \mathrm{UO}_{2}$ rods with an enrichment of $1.806 \mathrm{wt} . \%$ and a pitch of $1.837 \mathrm{~cm}$; an outer zone of $176 \mathrm{U}_{\text {metal }}$ rods for these experiments, $0.947 \mathrm{wt} \% \%$ and $2.917 \mathrm{~cm}$; a varying water gap between the two zones because of the two different pitches. The picture of the reactor and critical assembly configuration is shown on Figure 4.

Both uranium fuels consist of a 1-m pile of cylindrical pellets cladded in aluminum. The rods are maintained vertically by two octagonal aluminum grid plates spaced $1 \mathrm{~m}$ apart. In the COLIBRI program, the grids have a $1 \mathrm{~mm}$ cadmium layer to limit axial neutron leakage to the environment, i.e. structures activation, with the active zone of the fuel starting in the middle of the lower cadmium layer.

\section{B. The COLIBRI experimental setup}

The COLIBRI fuel rods oscillator is designed to simultaneously oscillate any of 18 metallic uranium fuel rods laterally in the west region of the core periphery zone. It consists of two moving plates set above and below the core grids, and rigidly connected by an aluminum beam (see Figure 5). Each plate carries an extremity of the fuel rods, top and bottom respectively. The top moving plate is fixed on the superior grid via gliders. Its oscillation is produced by a motor: the motor rotation is converted to a linear translation using an eccentric sheave and a rod. The oscillation is transferred to the bottom moving plate via the aluminum beam. The bottom moving plate is not constrained by gliders, it is displaced only because of its connection to the transmission beam.

The selection of the moving fuel rods is performed by letting the rods lay on the reactor base plate (non-moving), or suspend them up $10 \mathrm{~mm}$ above the base plate to insert them in the moving plates. Top and bottom end caps are fixed to each rod to allow the insertion in the enlarged holes of either the static grids or the moving plates. The weight of the oscillating rods is supported by a platform. The amplitude of the oscillation is precisely tuned by changing the eccentricity of the sheave with calibration plates, $0.5 \mathrm{~mm}$ by $0.5 \mathrm{~mm}$ from 0 to $\pm 2.5 \mathrm{~mm}$. Its frequency is depending on the speed of the motor.

The oscillation is controlled and monitored via a LabVIEWdeveloped software with $10 \mathrm{~ms}$ time-steps. An inductive captor is set at the rotation axis (i.e. at the top), which detects the actual movement of the motor by detecting the passage of four metallic pins per rotation. A cable coder is used to measure the displacement of the moving plate, i.e. at the bottom, with a 
$0.1 \mathrm{~mm}$ precision. The software produces a csv file output with the recordings of the motor position and speed, the signal of the inductive captor, and the position measurement of the cable. A typical recording of an oscillation is presented in Figure 6. The inductive captor signal is also extracted for live and synchronized recording with the detection instrumentation.

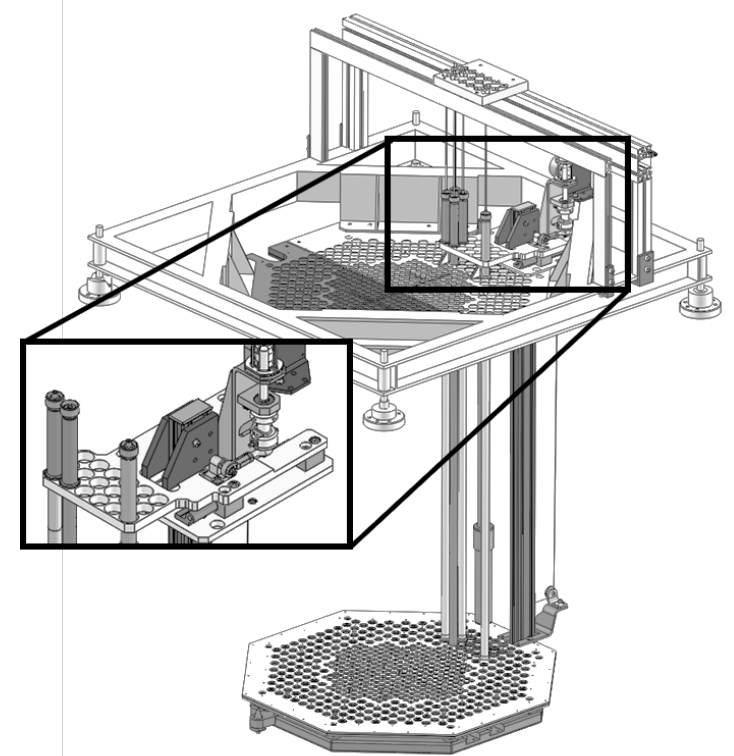

Fig. 5. The fuel rods oscillator with core structures and a few rods inserted in the device (right).

The behavior of the oscillator has been characterized in air and in water, out of the vessel and in-core, empty, 1-rod and 18rods loaded [11]. The behavior in frequency is sound. In amplitude, the device is rigid at the top, depending only on the rotation to translation conversion, and limited plays associated. At the bottom, it demonstrates inertia effects inducing an increase of the amplitude for the full 18-rods load case and above $1 \mathrm{~Hz}$. This effect cannot be corrected, and thus has to be taken into account as is. The static reactivity worth of the 18 rods was measured at about $10 \mathrm{ct}$ in total for a maximal amplitude of $\pm 2.5 \mathrm{~mm}$.

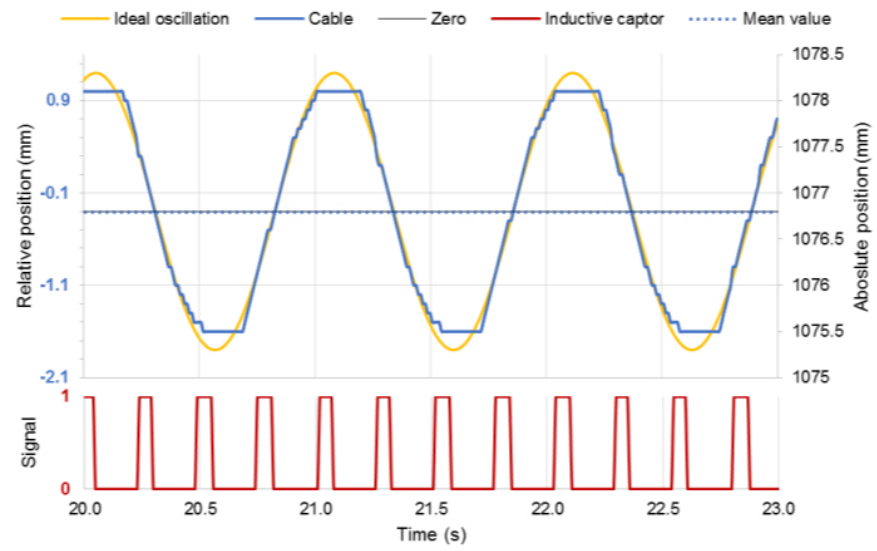

Fig. 6. Cable (blue) and inductive captor (bottom, red) signals provided by the control system (case: 1 rod in air, $\pm 1.5 \mathrm{~mm}$ and $1 \mathrm{~Hz}$ ).

\section{Neutron detection instrumentation}

The detection instrumentation comprised the facility monitors, and different types of additional ex-core and in-core detectors, for a total of eleven detectors of various sizes and sensitivities:

- two operation monitors ${ }^{10} \mathrm{~B}$-coated compensated ionization chambers (CIC): Merlin-Gerin CC54,

- two safety monitors ${ }^{235} \mathrm{U}$-coated fission chambers (FC): Photonis CFUM21,

- two ex-core large ${ }^{235} \mathrm{U}$-coated fission chambers: Photonis CFUL01,

- two in-core small $\mathrm{BF}_{3}$ proportional counters (PC): Transcommerce International $\mathrm{MN}-1$,

- two in-core smaller $\mathrm{BF}_{3}$ proportional counters

- one in-core ${ }^{235} \mathrm{U}$-coated miniature fission chamber (MFC): Photonis CFUF34.

All detectors are based on prompt detection processes. The location of each of them with regards to the core and COLIBRI are presented in Figure 7. All four monitor detectors are set at reference positions, as presented in the CROCUS benchmark. The other detectors were set vertically at core mid-height. On the horizontal plane, the large CFUL01 fission chambers were set in the reflector at west (close to COLIBRI) and east positions. The $\mathrm{BF}_{3}$ counters were set at positions within the lattice as presented in Figure 7, in the control rod guide tube for the NW one (detector 3), and in aluminum channels for the others. The miniature fission chamber was set at core center. The general uncertainty on detector position is $\pm 1 \mathrm{~mm}$.

The operation ionization chambers and the large fission chambers were operated in current mode [2], whereas all the other detectors were operated in pulse mode using spectrometry charge preamplifiers. The detectors and their electronics were connected to the ISTec, TUD, and both EPFL pulse and current mode instrumentations, with a number of detectors depending on the number of possible inputs [6]. In addition, the safety monitors were used in MCS mode for power monitoring.

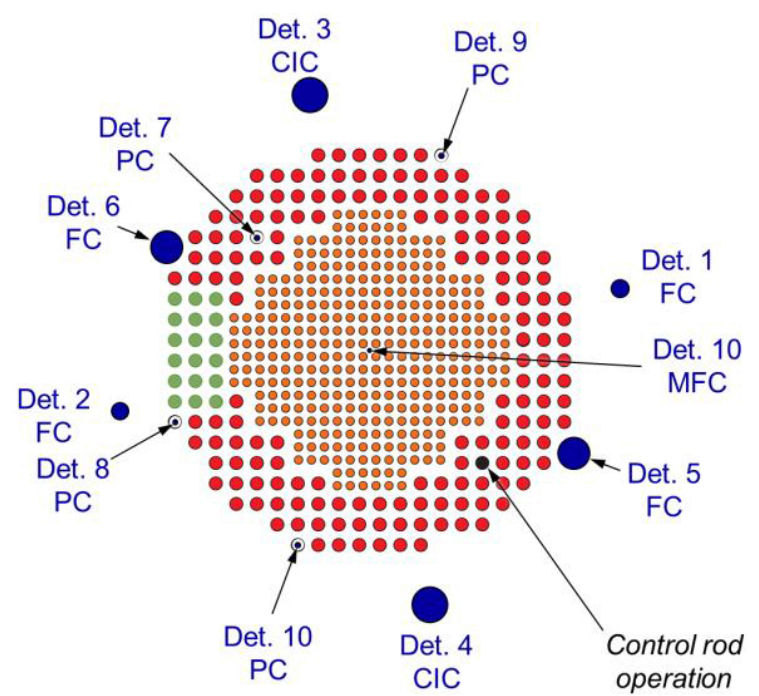

Fig. 7. Top view of the COLIBRI configuration for the $1{ }^{\text {st }}$ CORTEX campaign with location of the perturbation (green), neutron detectors, and control rod. 


\section{Experiments}

Two types of measurements were carried out: static, and a range of measurements in oscillation. The reactor was operated with the south control rod (see Figure 7), at a fixed water level of $1000 \pm 0.1 \mathrm{~mm}$. Following linearity tests, the power was set around $100 \mathrm{~mW}$, and the water temperature was controlled at $20.0 \pm 0.1{ }^{\circ} \mathrm{C}$. In all cases, the 18 rods were lifted in the oscillation position: in the static case, the motor was off and the position was set at zero, i.e. in their nominal position within the lattice. The global reactivity effect of the oscillations was compensated to follow a stable power. In practice, the oscillation was started first, then the reactor was stabilized in power with the control rod before starting the measurement. The control rod insertion was updated along the operation and measurement.

The experiments are listed in Table I. 20 measurements were carried out in total, with limited repetition. All measurements were acquired by all four systems. The duration of each measurement was chosen to cover enough cycles of the perturbation oscillation, around 1000 except for $0.1 \mathrm{~Hz}$, with a minimum time of $30 \mathrm{~min}$ for resolving the zero power noise. Amplitudes of limited waves at the water surface induced by oscillations were measured using the reactor instrumentation (INUS ultrasonic sensor). The oscillation is listed here in requested displacement amplitude and frequency, with a difference between requested and measured ones due to the system limitations [11]. In addition to the neutron detection signals, three other outputs were recorded:

- the synchronized signal from the inductive captor,

- the oscillator's structured output, including motor, inductive captor, and cable,

- $\quad$ the two power monitors outputs.

TABLE I

LIST OF OSCILLATION EXPERIMENTS IN CROCUS

\begin{tabular}{cccccc}
\hline \hline & \multicolumn{5}{c}{ Measurement duration for each frequency (min) } \\
$\begin{array}{c}\text { Amplitude } \\
(\mathrm{mm})\end{array}$ & $0.1 \mathrm{~Hz}$ & $0.5 \mathrm{~Hz}$ & $1.0 \mathrm{~Hz}$ & $1.5 \mathrm{~Hz}$ & $2.0 \mathrm{~Hz}$ \\
\cline { 2 - 6 } & 60 & 30 & 30 & - & - \\
\hline 0.5 & 60 & 30 & 30 & 30 & 30 \\
\pm 1.0 & $60^{*}$ & 30 & $120^{*}$ & 30 & 30 \\
\pm 1.5 & 60 & 30 & 30 & - & - \\
\pm 2.0 & & & & & \\
\hline * with repetition
\end{tabular}

with repetition.

\section{CONCLUSION AND OUTLOOK}

The first CORTEX experimental campaigns in the AKR-2 and CROCUS reactors were successfully carried out in 2018. The focus was on the acquisition of reference data set to qualify the acquisition systems, start the validation of the modelling tools developed within the Consortium, and orient the next campaigns. The analysis of the experiments is on-going for their comparison with the simulation results. The next campaigns are planned in 2019 and 2020 in CROCUS and AKR-2, respectively.

\section{ACKNOWLEDGMENT}

The authors would like to thank the operation teams at both reactor facilities for their help and dedication to the experiments.

\section{REFERENCES}

[1] C. Demazière, P. Vinai, M. Hursin, S. Kollias, and J. Herb, "Overview of the CORTEX project," in PHYSOR 2018: Reactor Physics Paving The Way Towards More Efficient Systems, 2018, pp. 2971-2980.

[2] O. Pakari, V. Lamirand, G. Perret, P. Frajtag, and A. Pautz, "Kinetic Parameter Measurements in the CROCUS Reactor Using Current Mode Instrumentation," IEEE Trans. Nucl. Sci., vol. 65, no. 9, pp. 2456-2460, 2018.

[3] V. Lamirand, G. de Izarra, A. Krasa, G. Perret, O. V. Pakari, M. Hursin, P. Blaise, J. Wagemans, and A. Pautz, "Intercomparison of neutron noise measurement systems in the CROCUS reactor," in Proceedings of PHYSOR 2018, 2018, p. 11.

[4] M. Hursin, O. Pakari, G. Perret, P. Frajtag, V. Lamirand, I. Pazsit, V. Dykin, G. Por, H. Ferroukhi, and A. Pautz, "Measurement of the gas velocity in a water-air mixture in CROCUS by neutron noise technique," in International Conference on Mathematics and Computational Methods applied to Nuclear Science and Engineering (M\&C 2019), 2019.

[5] B. Boehmer, M. Grantz, W. Hansen, D. Hinke, J. Konheiser, H.-C. Mehner, K. Noack, R. Schneider, I. Stephan, and S. Unholzer, "Investigation of Gamma and Neutron Energy Fluences in Iron Water Benchmark Configurations for the Verification of Monte Carlo Calculations and their Application in Reactor Material Dosimetry," J. Nucl. Sci. Technol., vol. 39, no. sup2, pp. 947-950, 2002.

[6] A. Rais, V. Lamirand, O. Pakari, A. Laureau, J. Pohlus, C. Pohl, M. Hursin, C. Demazière, and A. Pautz, "Towards the validation of neutron noise simulators: qualification of data acquisition systems," in International Conference on Mathematics and Computational Methods applied to Nuclear Science and Engineering (M\&C 2019), 2019.

[7] V. Lamirand, M. Hursin, G. Perret, P. Frajtag, O. Pakari, and A. Pautz, "Future experimental programmes in the CROCUS reactor," in RRFM/IGORR 2016, 2016, no. 02-2016, pp. 284-292.

[8] V. Lamirand, P. Frajtag, D. Godat, M. Hursin, G. Perret, O. V. Pakari, A. Laureau, A. Rais, C. Fiorina, M. Chadwick, and A. Pautz, "The COLIBRI programme in CROCUS: development and licensing of a fuel rods oscillator," in RRFM/IGORR 2019, 2019.

[9] U. Kasemeyer, R. Früh, J. M. Paratte, and R. Chawla, "Benchmark on Kinetic Parameters in the CROCUS Reactor," in International Reactor Physics Experiments Handbook (IRPhE), no. 4440, OECD, Ed. 2007, p. 94.

[10] J. M. Paratte, R. Früh, U. Kasemeyer, M. a. Kalugin, W. Timm, and R. Chawla, "A benchmark on the calculation of kinetic parameters based on reactivity effect experiments in the CROCUS reactor," Ann. Nucl. Energy, vol. 33, no. 8, pp. 739-748, May 2006.

[11] V. Lamirand, P. Frajtag, D. Godat, M. Hursin, G. Perret, O. Pakari, A. Rais, C. Fiorina, and A. Pautz, "The COLIBRI programme in CROCUS : characterisation of the fuel rods oscillator," in ANIMMA 2019, 2019. 